\title{
Oral cancer in young adults: report of three cases and review of the literature
}

\author{
R. J. Oliver, ${ }^{1}$ J. Dearing, ${ }^{2}$ and I. Hindle, ${ }^{3}$
}

\begin{abstract}
Oral cancer in young adults is fortunately uncommon in the UK. However, since it is so rare, when cases present they are often misdiagnosed and inappropriately treated leading to delay in definitive treatment. This may, in turn, lead to a poorer prognosis for these patients. It is debatable if oral cancer in younger adults carries an inherently poor prognosis and presents with more aggressive tumours. Three cases of oral cancer in young adults, aged under $\mathbf{3 0}$ years are presented and the literature reviewed with respect to oral cancer in this group of patients.
\end{abstract}

$\mathrm{O}^{\mathrm{r}}$ ral cancer (ICD 141, 143-146) continues to be a serious problem in the UK with a steadily rising incidence in certain birth cohorts. ${ }^{1}$ Despite this, oral cancer remains primarily a disease of older patients. Cases occurring in younger adults are uncommon, in the region of $1 \%$ of oral cancers in England and Wales; ${ }^{2}$ arbitrarily a younger age group is referred to as less than 30 or 40 years. However, in the majority of reports as in the present, a group of otherwise apparently healthy young adult patients often without any of the usual risk factors for the development of oral cancer are identified. However, even when young patients have indulged in the risk factors of tobacco and alcohol, it is for considerably shorter periods compared with the older age group. Patients in this younger age group are claimed by some to have a more aggressive disease with a higher incidence of local recurrence or regional lymph node involvement after treatment and a higher mortality rate compared with older patients ${ }^{3,4}$ while others do not support this notion. ${ }^{5-8}$

\footnotetext{
${ }^{1}$ Lecturer, ${ }^{3}$ Senior Lecturer, Oral Surgery Unit, University Dental Hospital of Manchester, Higher Cambridge Street, Manchester M15 6FH; ${ }^{2}$ Medical House Officer, Birmingham Heartlands Hospital, Bordesley Green, Birmingham B95SS

Correspondence: Dr Richard Oliver, Dental Medicine and Surgery, University Dental Hospital, Higher

Cambridge Street, Manchester M15 6FH

email:richard.j.oliver@man.ac.uk

REFEREED PAPER

Received 15.06.99; accepted 22.11.99

(C) British Dental Journal 2000; 188: 362-366
}

We are reporting a series of cases of oral cancer occurring in three apparently healthy Caucasian adult patients aged 20, 24 and 26 years old who presented to one consultant in a 12 -month period.

\section{Case reports}

Case 1

A 26-year-old married male presented for routine examination with his general dental practitioner, complaining of a sore area on the left side of his tongue, present for about 1 week. There was no relevant medical history, and the patient was a non-smoker who drank around 10 units of beer per week. The practitioner diagnosed a traumatic ulcer, prescribed triamcinolone in carmellose and a chlorhexidine mouthwash. Reviewing the patient 1 week later, the ulceration was found to have healed, leaving

In brief

- Oral cancer chiefly affects older adults.

- In younger adults, oral cancer is often not considered because of its relative infrequency which may lead to late referral for treatment.

- Young adult patients who develop oral cancer often are not exposed to the traditional risk factors of tobacco and alcohol. an area of leukoplakia tender to palpation. At review 1 month later the white patch had become nodular and the patient was referred. At presentation 3 days later the symptoms of pain from the left side of the tongue continued, exacerbated by spicy foods but not relieved by empirical treatments received from the practitioner. Intraorally, a $25 \mathrm{~mm}$ diameter white, verrucous area extended from the left lateral margin of the tongue into the sublingual area which was tender to palpation. The tissue proximal to the lesion was erythematous and atrophic in appearance.

The lesion was biopsied and histopathological examination revealed a well differentiated squamous cell carcinoma. The patient underwent total excision of the lesion with reconstruction using a split skin graft. At 5 -year follow-up the patient remained free from disease.

Case 2

A 24-year-old married female was referred urgently having presented to her general medical practitioner complaining of a lump under her tongue of about 3 weeks duration. On presentation, she admitted to a lump on the right side of her tongue which had previously been asymptomatic but had begun to cause occasional discomfort as it increased in size. The lump was interfering with the patients ability to eat. Previous medical history revealed that the patient had undergone cervical diathermy to remove severely dysplastic cells, which had been diagnosed as CIN III (cervical intraepithelial neoplasia grade III). Otherwise her medical history was clear, and the patient was teetotal but smoked up to 20 cigarettes per day. Extraoral examination revealed the presence of right hand side jugulodigastric lymphadenopathy. Intraorally there was evidence of swelling on the right lower lateral border of the tongue extending into the floor of the mouth, which was tender and indurated (Figure 1). There was no fixation of the mass to the mandible. An incisional biopsy was performed and histopathologically demon- 
Fig. 1 Lesion on the right lateral border of the tongue of Case 2 (24-year-old female)

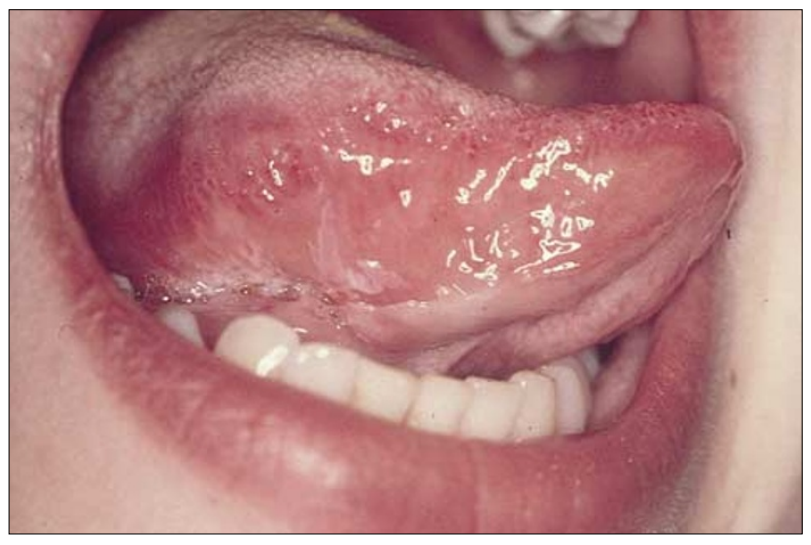

strated well differentiated squamous cell carcinoma.

Bone scans and chest computed tomogram (CT) were clear. CT revealed two abnormal nodes in the right jugulodigastric region and one on the left which were needle biopsied; the left hand side node was negative but the right nodes showed metastatic squamous cell carcinoma. Following surgery and radiotherapy the patient was still alive and well with no evidence of recurrent disease more than 5 years after presentation. She subsequently gave birth to her first child.

\section{Case 3}

A 20-year-old female, was referred by her general dental practitioner regarding a $20 \mathrm{~mm}$ by $3 \mathrm{~mm}$ asymptomatic ulcerative lesion on the right lateral border of the tongue. This had been present for 3 weeks and had gradually reduced in size. The patient was unaware of the lesion, which had never caused any symptoms. There was no relevant medical history. The patient consumed minimal alcohol and smoked up to 30 cigarettes per day. Her paternal uncle had died from laryngeal carcinoma. Intraorally an erosive lesion of the right lateral margin of the tongue with surrounding areas of hyperkeratinisation was noted. Incisional biopsy of the lesion was performed providing a histopathological diagnosis of erosive lichen planus with no evidence of neoplasia.

The patient was reviewed at monthly intervals. Six months post-biopsy she attended her general dental practitioner complaining of a lump on her tongue, was reassured and dismissed. A further 2 months later the patient attended her local accident and emergency department for treatment of a sudden haemorrhage from the right side of her tongue. The haemorrhage was arrested and the patient discharged with no advice to seek further assistance. Two days later she presented suffering from marked dysarthria and dysphagia. Extraoral examination revealed a tender, hard, enlarged right jugulodigastric lymph node. Intraoral examination demonstrated a large, tender, indurated ulcer on the right lateral border of the tongue (Figure 2). The patient was admitted and incisional biopsy of the lesion was performed which histopathologically was squamous cell carcinoma. Magnetic resonance imaging (MRI) showed that the lesion extended mesially to the midline of the tongue, inferiorly to the muscles of the floor of the mouth
Fig. 2 Ulcerated lesion on the right lateral border of the tongue of Case 3 (20-year-old female) illustrating that the lesion to taking the biopsy was haemorrhaging prior and posteriorly to the fauces without tonsillar involvement. Isotope bone scan and chest CT were clear, but MRI demonstrated abnormalities in the right jugulodigastric lymph nodes.

Despite radical surgery and radiotherapy the patient died 5.5 months after presentation.

\section{Discussion}

Oral cancer in young adults is uncommon and therefore case reports claiming its aggressiveness can be regarded as little more than anecdotal because of insufficient numbers to prove this hypothesis scientifically. The incidence of oral cancer is increasing in some cohorts of patients towards the younger end of the group of patients who develop oral cancer (those more than 40 years) $;^{1}$ the numbers of cases in young adults less than 40 years of age are so few it is not possible at the present time to say if the incidence in this age group is actually increasing. Clinical experience tells us that young adults presenting with and treated for this disease often have extensive primary tumours and develop recurrences locally or in regional lymph nodes, often succumbing to their disease rapidly. However, this is not always the case, as illustrated in the present series. Summarised data of previous studies of oral cancer in young adults is presented in Table 1.

Sarkaria and Harari reviewed a total of 152 cases of oral cancer in patients less than 40 years of age reported in the literature. $^{3}$ These authors concluded from this

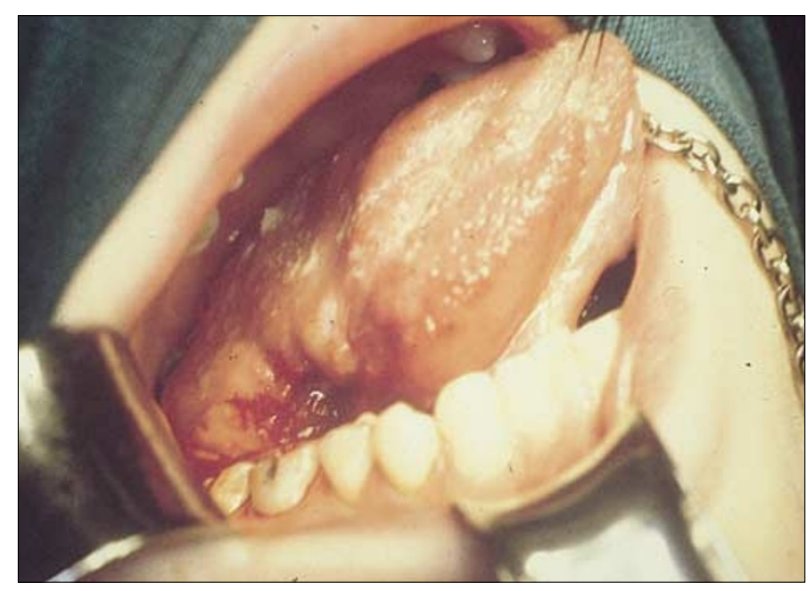


significant number that $57 \%$ experienced failure above the clavicles and that $47 \%$ of patients died from their cancer. However, recent statistics reveal that the 5 -year survival for oral cancer in general is in the region of $39 \% .^{9}$

In contrast to the above review of 14 papers, ${ }^{3}$ Rennie and McGregor reported a series of 13 cases of oral cancer in patients less than 40 years of age and concluded that younger patients had a prognosis similar to older patients. ${ }^{8}$ However, the age range of this group was between 33 and 39 years, with 11 out of 13 cases being smokers, 11 out of 13 being drinkers including 2 alcoholics; only one of their cases neither consumed alcohol nor smoked and this patient was alive and well after 4 years. In a similar vein, Lipkin et al. presented a series of head and neck cancers which included 15 cases in the oral cavity. ${ }^{10}$ These authors concluded that oral cancer in young adults could be associated with heavy smoking and alcohol consumption with an average consumption of 63 pack/years of tobacco. However, their cohort of patients was largely in the 35 to 40 year age group which some would not classify as truly 'young' adults.

Lund and Howard reviewed head and neck tumours in the under 35 year olds during a 22-year period which included 14 tumours of the tongue, 6 of the palate and 3 in the floor of the mouth. ${ }^{4}$ Detailed data were only available for the tongue tumours, all of which were squamous cell carcinomas. These authors noted a delayed presentation of these patients who had often been falsely reassured by other practitioners prior to referral. This fact may have accounted for their reported $75 \%$ mortality rate in this group. Their report, however, concluded that there was no increase in the rate of presentation in the younger patients. Indeed, in Case 3 of the present series, the patient was dismissed on two occasions when it was likely the carcinoma was present.

In a review of squamous cell carcinomas of the upper aerodigestive tract, Burzynski et al. included nine cases of the oral cavity with only two patients who died of disease, ${ }^{6}$ one patient was lost to follow-up and one died of other causes. These cases were all treated with surgery in the first instance.

\begin{tabular}{|c|c|c|c|c|c|}
\hline \multirow{2}{*}{ Table 1} & \multicolumn{5}{|c|}{ Previous reports of oral concer in young patients } \\
\hline & Reference & $\begin{array}{l}\text { Ages } \\
\text { (years) }\end{array}$ & $\begin{array}{c}\text { Number of } \\
\text { patients }\end{array}$ & $\begin{array}{l}\text { Local or } \\
\text { regional } \\
\text { failure }\end{array}$ & $\begin{array}{l}\text { Died of } \\
\text { disease }\end{array}$ \\
\hline $\begin{array}{l}\text { Burzynski et al (1992) } \\
\text { Lipkin et al (1985) } \\
\text { Lund and Howard (1990) } \\
\text { Rennie and McGregor (1987) } \\
\text { Sarkaria and Harari (1994)* } \\
\text { Sorensen et al (1997) } \\
\text { Present Study (1999) }\end{array}$ & $\begin{array}{r}6 \\
10 \\
4 \\
8 \\
3 \\
15\end{array}$ & $\begin{array}{l}<40 \\
<40 \\
<35 \\
<40 \\
<40 \\
<40 \\
<30\end{array}$ & $\begin{array}{r}9 \\
15 \\
14 \\
13 \\
152 \\
11 \\
3\end{array}$ & $\begin{array}{r}4 / 9 \\
N / S \\
N / S \\
9 / 13 \\
71 / 124 \\
N / S \\
1 / 3\end{array}$ & $\begin{array}{r}2 / 9 \\
19 / 30 \\
10 / 14 \\
9 / 13 \\
71 / 152 \\
4 / 11 \\
1 / 3\end{array}$ \\
\hline \multicolumn{6}{|c|}{$\begin{array}{l}\text { *A review of } 14 \text { publications, data was not available in all reports regarding recurrence } \\
\text { } \text { One patient lost to follow-up, one patient died of other causes } \\
\mathrm{N} / \mathrm{S}=\text { not stated }\end{array}$} \\
\hline
\end{tabular}

They reported that $91 \%$ of the whole group (23 patients) were current or previous tobacco users, however, data was not presented for the individual patients with oral cancer. Two of the patients in the present report were smokers, interestingly, both female. Smoking is strongly associated with the development of oral cancer in older patients ${ }^{11}$ but is not generally considered to be a significant aetiological agent in patients of the younger age group despite many of the reported cases showing this habit in these patients.

Assuming smoking and alcohol not to be significant in the aetiology of oral cancer in the young, the genetic events underlying the disease are difficult to account for. The tumour suppressor gene, p53, has been extensively studied and is the most consistently altered gene in oral cancer to date where it is particularly associated with heavy smoking. ${ }^{12}$ In oral cancer of the young, p53 mutations have been reported as being absent in non-smoking and non-drinking patients. ${ }^{13}$ Many young patients with oral cancer have a history of smoking, as two of the cases in the present report, so for these p53 may play a role but in the remainder of patients there is likely to be some other, as yet undetermined, genetic change. An increased susceptibility to carcinogenic agents has been reported in younger adult patients who have developed oral cancer, the details of which are outside the scope of this article and have been reviewed in a recent paper. ${ }^{14}$

A family history of oral cancer has been reported ${ }^{15}$ and positive family history of other cancers has been reported for young patients with oral cancer but this was not considered to be significant. ${ }^{16}$ Mork et al. recently reported a significantly increased odds ratios for developing head and neck squamous cell carcinoma in female patients, aged less than 45 years, who had first degree relatives with cancer. ${ }^{14}$

The role of viruses, particularly human papilloma virus (HPV), in oral cancer development is a much researched and debated area of study. Miller and White concluded in a review of the literature that HPV was a relatively ubiquitous virus and that its demonstration in a significant number of normal oral mucosae as well as in oral cancer was an effect rather than a cause. ${ }^{17}$ The link between HPV and cervical cancer, however, is stronger ${ }^{18}$ and it could be speculated there was a link in Case 2 between the development of CIN and oral cancer caused by HPV.

Some studies ${ }^{3,4}$ have claimed oral cancer in younger patients is more aggressive than in older patients and on the basis of this advocate more aggressive therapy. ${ }^{3}$ However, others have not reported any significant difference between the two groups. ${ }^{5-8}$ Von Doersten et al. using multivariate analysis investigated recurrence in head and neck cancer patients comprising nearly half of the oral cavity. ${ }^{19}$ They concluded that there was no significant difference between recurrence in the younger age group (15 to 39 years old) compared with the older age group and that more aggressive treatment was not necessary. In patients less than 40 
years of age with squamous cell carcinoma of the head and neck, including $21 \%$ of tumours in the mouth, Clarke and Stell reported crude survival $10 \%$ better in younger patients than older adults. ${ }^{7}$

Interestingly, one of the patients of the present series (Case 3) had histologically proven lichen planus which clinically presented in an erosive form. There is considerable controversy within the literature over the cancerous potential of lichen planus. Barnard et al. presented a series of cases of patients who developed squamous cell carcinoma in existing lichen planus and reviewed previously reported cases. ${ }^{20}$ These authors concluded that there was up to a $5 \%$ increase in the risk of developing carcinoma in lichen planus. Most reports of malignant change are in those lesions which are atrophic or erosive which could also be expected to be more susceptible to carcinogens. However, lesions of lichen planus occurring in the high risk sites of the lateral border of the tongue and floor of the mouth should still be regarded with some suspicion. Zhang et al. ${ }^{21}$ recently concluded that if malignant transformation occurred in lichen planus the genetic changes that took place were different from those of other precancerous lesions such as leukoplakia.

\section{Conclusions}

Oral cancer occurring in young adults is not common but nevertheless should always be considered in such patients when they present with persistent ulceration, leukoplakia, erythroplakia or swellings with no obvious local cause, particularly in the high-risk sites of the tongue and floor of the mouth. For any such lesion, a 'fasttrack' referral is recommended by telephone to the nearest specialist centre accompanied by a letter, usually sent with the patient. This will ensure prompt investigation and initiation of treatment which may increase the chances of successful treatment.

It remains unproven if oral cancer in younger patients is inherently more aggressive with a worse prognosis than the disease in older individuals. Personal encounters with such patients may be clouded by the potential emotional aspects of such a deadly disease occurring in younger patients.

With so few cases of oral cancer in younger adults it is still not possible to demonstrate a rising incidence. Improved registration of oral cancer should enable this aspect to be investigated further.

The aetiology of oral cancer in the younger adult remains unclear. It is likely there is some degree of genetic predisposition; genetic linkage studies of affected individuals and their families may prove useful investigating this. In some of the young adult patients, possibly those with an inherent genetic defect, smoking may have a role in the aetiology of oral cancer.

1 Hindle I, Downer M C, Speight P M. The epidemiology of oral cancer. Br J Oral Maxillofac Surg 1996; 34: 471-476.

2 Hindle I, Nally F. Oral cancer: a comparative study between 1962-67 and 1980-84 in England and Wales. Br Dent J 1991; 170: 15-19.

3 Sarkaria J N, Harari P M. Oral tongue cancer in young adults less than 40 years of age: rationale for aggressive therapy. Head And Neck 1994; 16: 107-111.

4 Lund V J, Howard D J. Head and neck cancer in the young: a prognostic conundrum? J Laryngol Otol 1990; 104: 544-548.

5 Verschuur H P, Irish J C, O’Sullivan B, Goh C, Gullane P J, Pintilie M. A matched control study of treatment outcome in young patients with squamous cell carcinoma of the head and neck. Laryngoscope 1999; 109: 249-258.

6 Burzynski N J, Flynn M B, Faller N M, Ragsdale T L. Squamous cell carcinoma of the upper aerodigestive tract in patients 40 years of age and younger. Oral Surg Oral Med Oral Pathol 1992; 74: 404-408.

7 Clarke R W, Stell P M. Squamous carcinoma of the head and neck in the young adult. Clin Otolaryngol 1992; 17: 18-23.

8 Rennie J S, McGregor A D. Intra-oral squamous cell carcinoma in patients under 40 years of age. A report of 13 cases and review of the literature. Br J Plastic Surg 1987; 40: 270-273.

9 Macfarlane G J, Sharp L, Porter S, Franceschi S. Trends in survival from cancers of the oral cavity and pharynx in Scotland: a clue as to why the disease is becoming more common? $\mathrm{Br}$ J Cancer 1996; 73: 805-808.

10 Lipkin A, Miller R H, Woodson G E. Squamous cell carcinoma of the oral cavity, pharynx, and larynx in young adults. Laryngoscope 1985; 95 : 790-793.

11 Franceschi S, Barra S, La Vecchia C, Bidoli E, Negri E, Talamini R. Risk factors for cancer of the tongue and the mouth. A case-control study from northern Italy. Cancer 1992; 70: 2227-2233.

12 Raybaud-Diogène $H$, Tétu $B$, Morency R,
Fortin A, Monteil R A. p53 overexpression in head and neck squamous cell carcinoma: review of the literature. Oral Oncology 1996; 32: 143-149.

13 Sorensen D M, Lewark T M, Haney J L, Meyers A D, Krause G, Franklin W A. Absence of p53 mutations in squamous carcinomas of the tongue in nonsmoking and nondrinking patients younger than 40 years. Arch Otolaryngol Head Neck Surg 1997; 123: 503-506.

14 Mork J, Moller B, Glattre E. Familial risk in head and neck squamous cell carcinoma diagnosed before the age of 45: a populationbased study. Oral Oncology 1999; 35: 360-367.

15 Ankathil R, Mathew A, Joseph F, Nair M K. Is oral cancer susceptibility inherited? Report of five oral cancer families. Oral Oncology 1996; 32B: 63-67.

16 Koch W M, McQuone S. Clinical and molecular aspects of squamous cell carcinoma of the head and neck in the nonsmoker and nondrinker. Current Opinion in Oncology 1997; 9: 257-261.

17 Miller C S, White D K. Human papillomavirus expression in oral mucosa, premalignant conditions, and squamous cell carcinoma. A retrospective review of the literature. Oral Surg Oral Med Oral Pathol Oral Radiol Endod 1996; 82: 57-68.

18 Anderson M C, Brown C L, Buckley C H et al. Current views on cervical intraepithelial neoplasia. J Clin Pathol 1991; 44: 969-978.

19 Von Doersten P G, Cruz R M, Rasgon B M, Quesenberry C P, Hilsinger R I. Relation between age and head and neck cancer recurrence after surgery: A multivariate analysis. Otolaryngol Head Neck Surg 1995; 113: 197-203.

20 Barnard N A, Scully C, Eveson J W, Cunningham S, Porter S R. Oral-cancer development in patients with oral lichenplanus. J Oral Pathol Med 1993; 22: 421-424.

21 Zhang L, Michelson C, Cheng X, Zeng T, Priddy R, Rosin M P. Molecular analysis of oral lichen planus. A premalignant lesion? Am J Pathol 1997; 151: 323-327.

A commentary on this paper follows on the next page 